\title{
Effect of the nanoparticles on the structure and crystallization of amorphous silicon thin films produced by rf glow discharge
}

\author{
E. Bertran, S. N. Sharma, and G. Viera \\ Departament de Fisica Aplicada i Optica, Universitat de Barcelona, Av. Diagonal 647, E 08028 \\ Barcelona, Spain \\ J. Costa \\ Departament d'Enginyeria Industrial, Universitat de Girona, Av. Lluis Santaló S/N, \\ E 17071 Girona, Spain \\ P. St'ahel and P. Roca i Cabarrocas \\ Laboratoire de Physique des Interfaces et des Couches Minces (CNRS, UPR 258), Ecole Polytechnique, \\ F-91128 Palaiseau Cedex, France
}

(Received 12 August 1997; accepted 20 November 1997)

Thin films of nanostructured silicon (ns-Si:H) were deposited by plasma-enhanced chemical vapor deposition in the presence of silicon nanoparticles at $100{ }^{\circ} \mathrm{C}$ substrate temperature using a silane and hydrogen gas mixture under continuous wave (cw) plasma conditions. The nanostructure of the films has been demonstrated by diverse ways: transmission electron microscopy, Raman spectroscopy, and x-ray diffraction, which have shown the presence of ordered silicon clusters (1-2 $\mathrm{nm}$ ) embedded in an amorphous silicon matrix. Because of the presence of these ordered domains, the films crystallize faster than standard hydrogenated amorphous silicon samples, as evidenced by electrical measurements during the thermal annealing.

\section{INTRODUCTION}

Plasma technology is used to produce thin films for microelectronics, and increasing interest has emerged in determining and controlling the effects of particles during the plasma processes. Since the work of Spears et al. ${ }^{1}$ on particles in $\mathrm{rf}$ discharge of silane, particles ranging from $10 \mathrm{~nm}$ to several tens of $\mathrm{nm}$ have been reported in different processes: etching, ${ }^{2}$ sputtering, ${ }^{3}$ and plasma enhanced chemical vapor deposition (PECVD). ${ }^{4}$ The microelectronics industry is concerned that the general trend of reduction of the device dimensions may be limited by the particle contamination from the plasma process itself. Nowadays, the undesirable role of the particles during the plasma processing has been questioned because the new properties found in silicon powders ${ }^{5,6}$ and in the silicon films ${ }^{7}$ grown in the presence of particles can be used in possible future applications as nanostructured materials..$^{5-8}$

In earlier studies on hydrogenated amorphous silicon $(a-\mathrm{Si}: \mathrm{H})$ thin films produced by PECVD, the powder formation was correlated to a deterioration of the film quality due to the production of pinholes, roughness, and porosity. ${ }^{9}$ Later, however, a study on the increase in the deposition rate and the decrease in the substrate temperature of silicon thin films ${ }^{10}$ concluded that the film properties were improved, in spite of the presence of powder during the plasma process. In particular conditions of low deposition rate $(<0.2 \mathrm{~nm} / \mathrm{s})$ using modulated $\mathrm{rf}$ power in the presence of powder, the ellipsometric measurements of the films revealed an increase in their density. ${ }^{11}$

This paper deals with a preliminary study of the main structural properties of the nanostructured silicon thin films (ns-Si:H) produced by setting the plasma parameters close to the powder formation. ${ }^{5}$ In these conditions, nanometric particles $(<2 \mathrm{~nm})$ are produced, they are not all confined within the plasma by the plasma-sheath (because of the charge fluctuation), and they can be incorporated to the growing film. ${ }^{7,12}$ In these films, silicon ordered domains (consisting of 3 to $5 \mathrm{Si}$ crystalline planes) were found to be embedded in the amorphous matrix.

In earlier works concerning the crystallization of $a$ $\mathrm{Si}: \mathrm{H}$ thin films, the results concentrated on the furnace annealing at $550-950{ }^{\circ} \mathrm{C}$ for several hours or rapid thermal annealing (RTA) at $700{ }^{\circ} \mathrm{C}$ for several minutes. ${ }^{13}$ In the present study, our ns-Si:H thin films have similar crystallization temperatures (around $590{ }^{\circ} \mathrm{C}$ ), but it could be attained faster than conventional $a$-Si:H films, as shown by electric current monitoring during the annealing. This may be related to the presence of nanosized silicon ordered domains acting as nuclei for crystallization. The results suggest that the initial crystal growth from the seeds of the Si film (here, the ordered domains) upon annealing is easier and faster than the grain growth without such seeds, as in the case of conventional $a$-Si: $\mathrm{H}$ films. These properties can open new ways to the application of this material. 


\section{EXPERIMENTAL DETAILS}

Thin films of ns-Si:H were deposited on 7059 Corning glass in a capacitively coupled radio-frequency $(13.56 \mathrm{MHz})$ PECVD reactor. The reaction chamber consists of a cylindrical box between two parallel stainless-steel electrodes of $15 \mathrm{~cm}$ diameter, $2.8 \mathrm{~cm}$ apart. This plasma box enabled a laminar flow to be piped through the plasma, from the edge of the bottom electrode (cathode), and flow out through the edges of the sample plated on the grounded electrode. The optimization of the plasma parameters to grow silicon films in the presence of nanoparticles, out of the powder formation, was carried out by means of light-scattering and transmission electron microscopy (TEM) measurements. ${ }^{7}$ Nanostructured silicon films (ns-Si:H) were obtained under a wide range of conditions. Here, we focus on the characterization of $\mathrm{ns}-\mathrm{S}: \mathrm{H}$ films produced with the following discharge conditions: $100{ }^{\circ} \mathrm{C}$ substrate temperature, $8 \mathrm{sccm}$ of $\mathrm{SiH}_{4}, 100 \mathrm{sccm}$ of $\mathrm{H}_{2}$, total pressure of $6 \mathrm{~Pa}$, and $\mathrm{rf}$ power density of $11 \mathrm{~mW} / \mathrm{cm}^{2}$ in continuous wave (cw) plasma. The ns-Si : $\mathrm{H}$ thin film and a standard $a-\mathrm{Si}: \mathrm{H}$ sample were coated with two bands of $\mathrm{Cr}$ which were $2 \mathrm{~mm}$ apart, and they were introduced at room temperature in a furnace at a pressure of $10^{-4} \mathrm{~Pa}$. The samples were heated to $590{ }^{\circ} \mathrm{C}$ in $30 \mathrm{~min}$. The current through the sample under the applied voltage of $10 \mathrm{~V}$ was then measured as a function of time. High resolution transmission electron microscopic (HRTEM) images and electron diffraction patterns were obtained with a Philips CM30 microscope operating at $300 \mathrm{kV}$. Micro-Raman backscattering measurements were performed with the $514 \mathrm{~nm}$ line of an Ar laser. For the as-deposited ns$\mathrm{Si}: \mathrm{H}$ thin film, the Raman spectrum was obtained at low power density $\left(1 \mathrm{~mW} / \mu \mathrm{m}^{2}\right)$ and with short exposure time in order to avoid thermal or crystallization effects. The x-ray diffractometry (XRD) was carried out in the grazing incidence diffraction mode $\left(\theta=1^{\circ}\right)$ using a Philips MRD diffractometer, with the $\mathrm{Cu} \mathrm{K}_{\alpha}$ $(\lambda=1.5418 \AA)$ radiation at $35 \mathrm{kV}$ and $40 \mathrm{~mA}$. In order to calculate the crystallite sizes of the samples from the XRD patterns, the $\mathrm{x}$-ray peaks were decomposed into two Lorentzian/Gaussian peaks, one corresponding to amorphous $\mathrm{Si}$ and the other to crystalline $\mathrm{Si}$.

\section{RESULTS AND DISCUSSION}

Figure 1 shows the time evolution of the normalized electric current of a ns-Si:H film and a standard $a$ $\mathrm{Si}: \mathrm{H}$ film during an isothermal annealing at $590{ }^{\circ} \mathrm{C}$. The figure shows that the crystallization of the films, monitored by the increase in conductivity, is much faster in $\mathrm{ns}-\mathrm{Si}: \mathrm{H}$ than in $a$-Si: $\mathrm{H}$. This behavior is quite reasonable to expect since nucleation has already been initiated in the as-deposited films owing to the presence of nanoparticles.

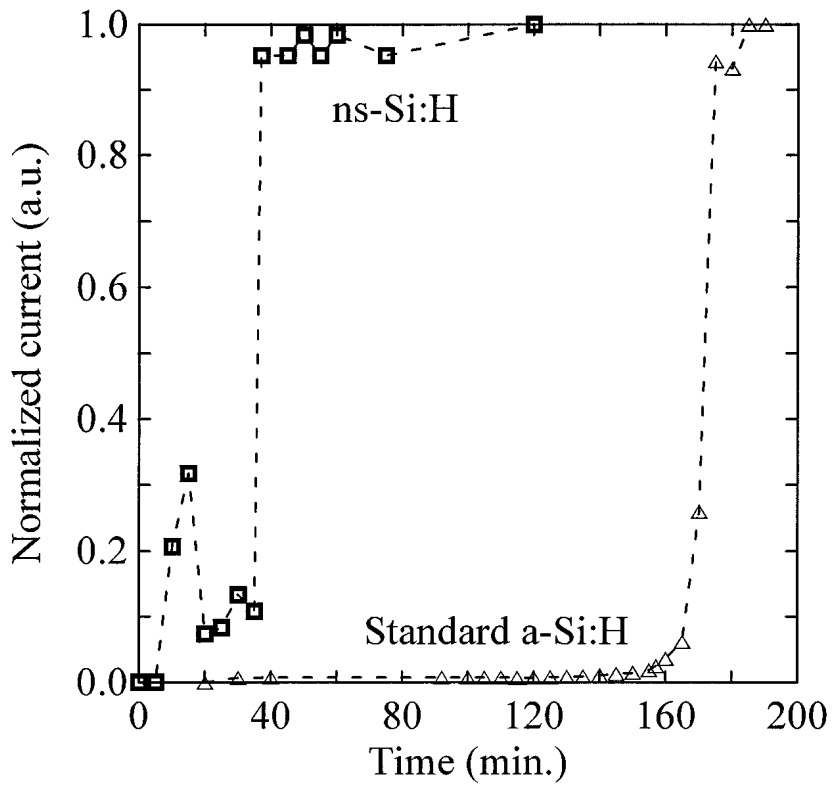

FIG. 1. Time evolution of the normalized electric current of the ns-Si: $\mathrm{H}$ and standard a-Si:H films during an isothermal annealing at $590{ }^{\circ} \mathrm{C}$.

HRTEM of the as-deposited ns-Si:H thin film corroborates the presence of small ordered domains, some of which are marked by arrows, as shown in the left micrograph of Fig. 2, and they are found to be embedded in an amorphous silicon matrix. Here, the order is limited to four or five planes of $\mathrm{Si}$ atoms, with an average crystallite size of around $1.5 \mathrm{~nm}$. Direct measurement reveals that the spacing of the atomic planes is $0.37 \mathrm{~nm}$. The corresponding electron diffraction pattern, as shown in the inset in the micrograph, shows diffused but distinct
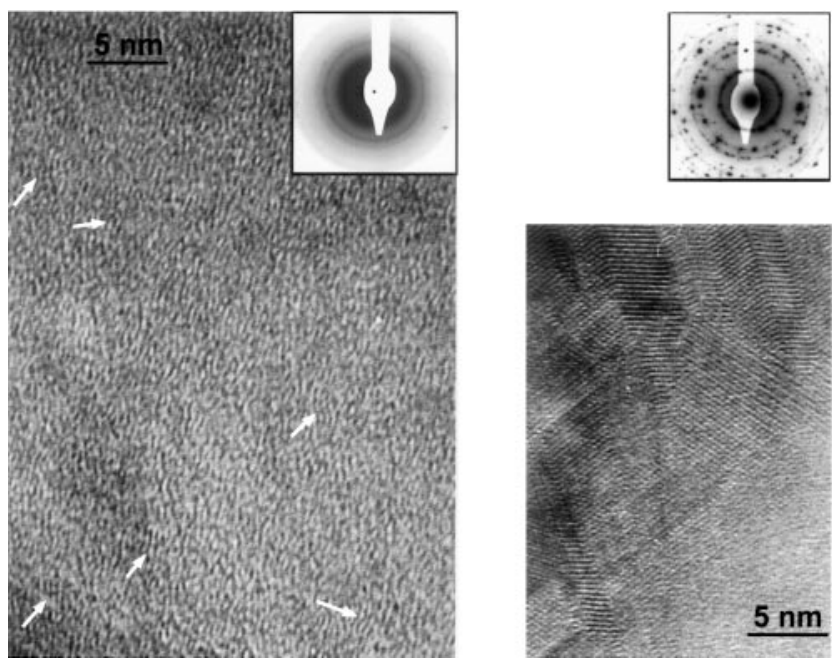

FIG. 2. High resolution TEM images of as-deposited ns-Si: $\mathrm{H}$ film (on the left) and after annealing at $590{ }^{\circ} \mathrm{C}$ (on the right). The insets in both micrographs denote their corresponding electron diffraction patterns, respectively. The arrows indicate some of the nanometric ordered domains inside the amorphous silicon matrix. 
rings, thus indicating that the structure of the film is composed of both an amorphous phase and a crystalline one. After annealing at $590{ }^{\circ} \mathrm{C}$, emergence of a large number of atomic planes of $\mathrm{Si}$, with interplanar distance around $0.31 \mathrm{~nm}$ corresponding to (111) planes of $\mathrm{Si}$ diamond-like structure, is observed from the HRTEM micrograph on the right of Fig. 2. Here (bottom right), amorphous matrix was also seen, which points to a process of heterogeneous crystallization that starts with the growth of the nanosized silicon clusters. The enhanced crystallinity is also evident from its electron diffraction pattern, which contains dotted rings superimposed on bright, continuous sharp rings, corresponding to (111), (220), and (311) planar spacing in Si diamondlike structure, thus indicating the random orientation of the crystals under the electron beam.

Figures 3(a) and 3(b) show the x-ray diffraction patterns of a nanostructured silicon sample before and after annealing, respectively. From Fig. 3(a), nanocrystalline features can be identified with the appearance of a distinct broad band corresponding to (111) peak and from a slight hump corresponding to a combination of (220) and (311) peaks. Similar x-ray patterns were also obtained by Veprek et al. ${ }^{14}$ and He et al. ${ }^{15}$ with crystallite size between 1 and $5 \mathrm{~nm}$. The average crystallite size can be calculated from the full-width at half-maximum (FWHM) and the peak position of the (111) x-ray mode using Scherrer's formula. ${ }^{16}$ We obtained approximately $1.1 \mathrm{~nm}$, which is compatible with the TEM results. For the sample after annealing at $590{ }^{\circ} \mathrm{C}$ [Fig. 3(b)], the

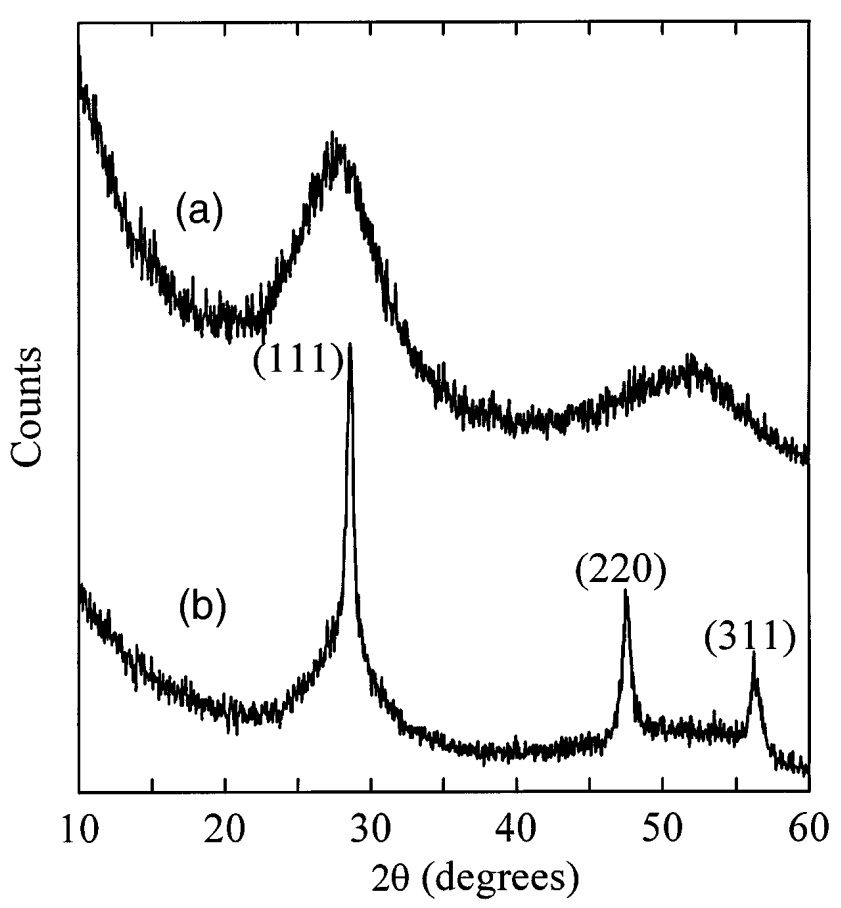

FIG. 3. X-ray diffraction spectra: (a) as-deposited ns-Si : H film and (b) after annealing at $590{ }^{\circ} \mathrm{C}$. background represents an amorphous matrix while the crystalline signatures are evident from (111), (220), and (311) x-ray diffraction peaks, in total agreement with the TEM observations. Here, the crystallite size was found to be $15.4 \mathrm{~nm}$. Similar x-ray diffraction patterns are generally shown by conventional undoped $\mu c$-Si films. ${ }^{17}$

The Raman spectrum for the as-deposited ns-Si: $\mathrm{H}$ sample is shown in Fig. 4. The inset in Fig. 4 shows the Raman spectrum for the annealed sample. It is evident that the Raman spectrum for the as-deposited ns-Si:H sample shows the characteristics features of amorphous silicon (i.e., LO mode at $440 \mathrm{~cm}^{-1}$ and a TO mode at $480 \mathrm{~cm}^{-1}$ ) and crystalline silicon (with TO mode at $518 \mathrm{~cm}^{-1}$ ), respectively. In view of the TEM and XRD results, the origin of these amorphous and crystalline peaks may be attributed to two different structural phases in the as-deposited films. Upon annealing of the asdeposited ns-Si: $\mathrm{H}$ at $590{ }^{\circ} \mathrm{C}$, a typical characteristic crystalline mode at $518 \mathrm{~cm}^{-1}$ with FWHM of $7 \mathrm{~cm}^{-1}$ is obtained (inset in Fig. 4). Here, the laser beam was focused on the crystallized portion during the Raman measurements.

All these features suggest that the $\mathrm{ns}-\mathrm{Si}: \mathrm{H}$ thin film consists of two phases: ordered domains of 1-2 $\mathrm{nm}$ and

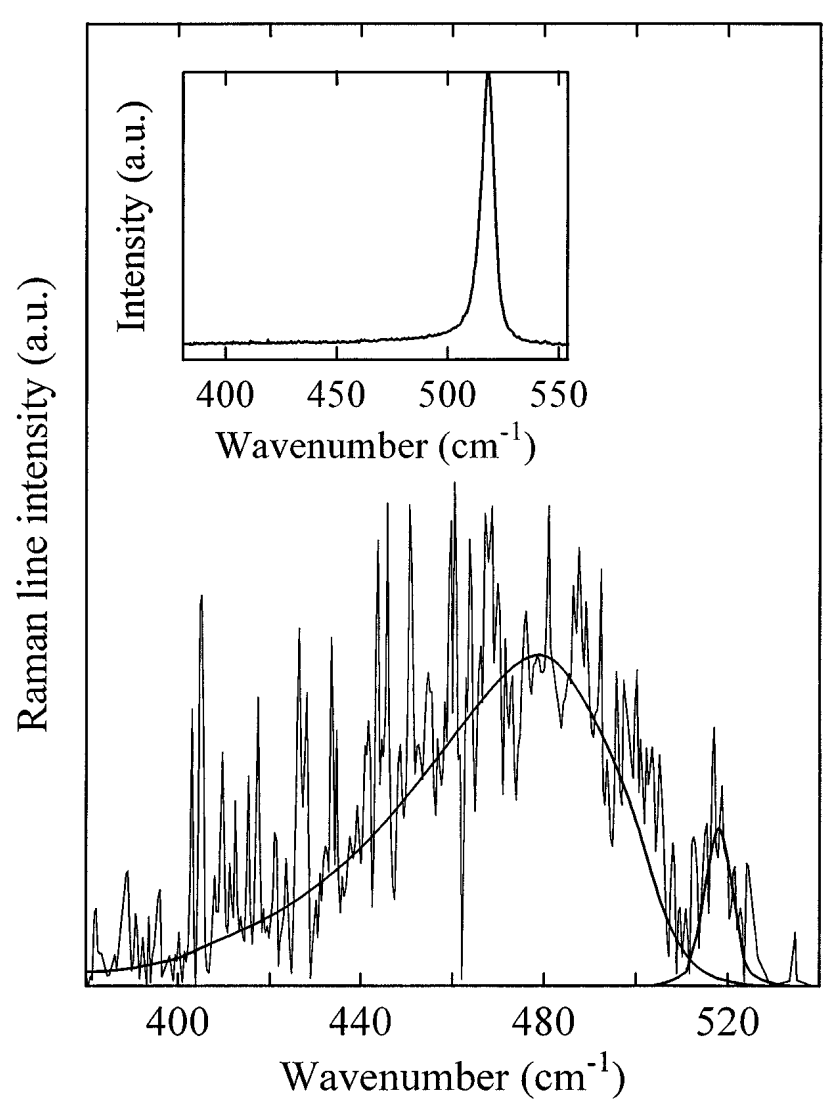

FIG. 4. Raman backscattering spectra of as-deposited ns-Si:H film. The inset in the figure corresponds to the Raman spectra for ns-Si: $\mathrm{H}$ film after annealing at $590{ }^{\circ} \mathrm{C}$. 
an amorphous matrix. The origin of these domains may be related to the particular deposition plasma conditions that favor the formation of small silicon particles. ${ }^{18} \mathrm{Be}-$ cause of their size, these particles of 1-2 $\mathrm{nm}$ may rather be understood as hydrogenated Si clusters, of different crystalline structure to the $\mathrm{Si}$ diamond-like structure. ${ }^{19}$ This may explain the large distance $(0.37 \mathrm{~nm})$ between planes determined experimentally in the ordered regions as compared to (111) planes of $\mathrm{Si}$ of the diamond structure which are about $0.31 \mathrm{~nm}$. These Si clusters may have acted as seeds for the rapid crystallization which was dominated by a heterogeneous nucleation process, in contrast to the standard a-Si:H thin films.

\section{CONCLUSION}

In summary, nanostructured silicon thin films were deposited by PECVD under $\mathrm{cw}$ plasma conditions at lower substrate temperature $\left(100{ }^{\circ} \mathrm{C}\right)$ and rf power density of $11 \mathrm{~mW} / \mathrm{cm}^{2}$ using silane diluted in hydrogen. The presence of ordered domains $(1-2 \mathrm{~nm})$ in the asdeposited silicon film, indicated by TEM, XRD, and Raman, facilitates the crystallization process induced by thermal annealing, because the small crystalline domains act as seeds for the crystallization.

\section{ACKNOWLEDGMENTS}

This work was partially supported by the CEC BRITE-EURAM program under Contract No. BE 7328 and cofinanced by the CICYT and MEC of Spain under Contract Nos. MAT94-1511-CE, MAT96-1194-C02-01 and by HF95-110 of the Acciones integradas HispanoFrancesas program, respectively. The authors thank Ives Maniette and Juan Carlos Ferrer for the TEM measurements, Mrs. $\mathrm{M}^{\mathrm{a}}$ Sol Cuñarro for her help in the digital treatment of the HRTEM photographs, Xavier Alcover for the XRD measurements, and Tariq Jawhari for the Raman measurements, all at the Serveis CientíficoTècnics of the University of Barcelona. One of the authors (S.N.S.) thanks the Generalitat de Catalunya within the PIR programme for his fellowship.

\section{REFERENCES}

1. K. G. Spears, T. J. Robinson, and R. M. Roth, IEEE Trans. Plasma Sci. PS-14, 179 (1986).

2. G. S. Selwyn, J. Singh, and R. S. Benett, J. Vac. Sci. Technol. A 7, 2758 (1989).

3. G. M. Jellum and D. B. Graves, J. Appl. Phys. 67, 6490 (1990).

4. Y. Watanabe, M. Shiratani, Y. Kubo, I. Ogawa, and S. Ogi, Appl. Phys. Lett. 53, 1263 (1988).

5. E. Bertran, J. Costa, G. Sardin, J. Campmany, J. L. Andújar, and A. Canillas, Plasma Sources Sci. Technol. 3, 348 (1994).

6. J. Costa, P. Roura, G. Sardin, J. R. Morante, and E. Bertran, Appl. Phys. Lett. 64, 463 (1994).

7. P. Roca i Cabarrocas, P. Gay, and A. Hadjadj, J. Vac. Sci. Technol. A 14, 655 (1996).

8. Molecularly Developed Ultrafine/Nanostructured Materials, edited by K.E. Gonsalves, G-M. Chow, T.D. Xiao, and R. C. Cammarata (Mater. Res. Soc. Symp. Proc. 351, Pittsburgh, PA, 1994).

9. R. C. Ross and J. Jaklik, J. Appl. Phys. 55, 3785 (1984).

10. P. Roca i Cabarrocas, J. Non-Cryst. Solids 164-166, 37 (1993).

11. A. Lloret, E. Bertran, J.L. Andújar, A. Canillas, and J.L. Morenza, J. Appl. Phys. 69, 632 (1991).

12. A. A. Howling, J-L. Dorier, and Ch. Hollenstein, Appl. Phys. Lett. 62, 1341 (1993).

13. C. W. Lee, C. Lee, and Y. T. Kim, Appl. Phys. A 56, 123 (1993).

14. S. Veprek, Z. Iqbal, and F. A. Sarott, Philos. Mag. B 45, 137 (1982).

15. Y. He, C. Yin, G. Cheng, L. Wang, X. Liu, and G. Y. Hu, J. Appl. Phys. 75, 797 (1994).

16. A. Guinier, in X-ray Diffraction (Freeman, San Francisco, CA, 1963), p. 124.

17. S. N. Sharma, A. K. Bandyopadhyay, R. Banerjee, A. K. Batabyal, and A. K. Barua, Phys. Rev. B. 43, 4503 (1991).

18. L. Boufendi, A. Plain, J. Ph. Blondeau, A. Bouchoule, C. Laure, and M. Toogood, Appl. Phys. Lett. 60, 169 (1992).

19. W. D. Leudtke and U. Landman, Phys. Rev. B 37, 4656 (1988). 